\title{
Comprehensive chemical study of the acidification of musts in Sherry area with calcium sulphate and tartaric acid
}

\author{
J. Gómez ${ }^{1, a}$, C. Lasanta $^{1}$, L. M. Cubillana-Aguilera ${ }^{2}$, J. M. Palacios-Santander ${ }^{2}$, R. Arnedo ${ }^{3}$, J.A. Casas ${ }^{3}$, B. Amilibia ${ }^{4}$, \\ and I. LLoret ${ }^{5}$ \\ ${ }^{1}$ Department of Chemical Engineering and Food Technology, Faculty of Sciences. University of Cadiz, 11510 Puerto Real, Spain \\ ${ }^{2}$ Department of Analytical Chemistry, Faculty of Sciences, University of Cadiz, 11510 Puerto Real, Spain \\ ${ }^{3}$ Bodegas González-Byass, C/Manuel María González, 12, 11403 Jerez de la Frontera, Spain \\ ${ }^{4}$ Grupo Estévez S.A. Carretera Nacional IV. Km 640, 11408 Jerez de la Frontera, Spain \\ ${ }^{5}$ Fundación Jerez, Control y Certificación, Avda, Alcalde Álvaro Domecq, 2, 11402 Jerez de la Frontera, Spain
}

\begin{abstract}
Calcium sulphate addition has traditionally been used in Sherry winemaking to reduce the necessary dose of tartaric acid. It is not easy to predict the final $\mathrm{pH}$ of a mixed tartaric acid and calcium sulphate addition and to determine the necessary doses to reach the final $\mathrm{pH}$ required by the winemaker because there are several interrelated chemical equilibra implied (tartaric acid dissociation, calcium tartrate and potassium bitartrate precipitation etc.). To predict the effect on $\mathrm{pH}$, several chemical modeling approaches have been described in the literature. It is noteworthy to mention the simplified model where the acidity of wine is considered to be due to a monoprotic acid. In this work the prediction of $\mathrm{pH}$ at industrial scale was confirmed and its practical application was facilitated by linear regression lines prepared with pilot scale data. Additionally, sensory analysis of wines acidified with calcium sulphate and tartaric acid alone and mixed indicates that there are great differences among them in taste and that mixed acidification is the preferred by the tasters. That confirms the good comprehension of the chemical equilibria involved in this practice and supply very useful information for its final approval in OIV.
\end{abstract}

\section{Introduction}

The acidification of musts during winemaking is made to reduce their $\mathrm{pH}$ to suitable values in order to inhibit bacterial activity, stabilize the color and improve the sensorial characteristics of the resulting wines. Furthermore, the intensity of the acidic taste of wines is directly related to the $\mathrm{pH}$ and its length with the buffering power [1]. Acidification of musts is more necessary in warm areas where high temperatures during ripening accelerate breathing combustion of tartaric acid and, in particular, malic acid in the berries [2]. L(+)-tartaric acid has traditionally been the only acidification agent used to date but the latest regulations of the OIV and European Union also authorize the use of L-malic acid, D,L-malic acid and lactic acid [3-5]. The maximum authorized doses are $1.5 \mathrm{~g} / \mathrm{L}$ in grape juice and $2.5 \mathrm{~g} / \mathrm{L}$ in wine, expressed as tartaric acid. The use of calcium sulphate $\left(\mathrm{CaSO}_{4} \cdot 2 \mathrm{H}_{2} \mathrm{O}\right)$ is authorized in the European Union as a complementary acidifier in generous and generous liquor wines from Spain provided that the residual sulphate content in the wine does not exceed $2.5 \mathrm{~g} / \mathrm{L}$ expressed as potassium sulphate. Calcium sulphate is also authorized in the United States for the production of wines aged under yeast veil although residual sulphate cannot exceed $2 \mathrm{~g} / \mathrm{L}$ [6]. Calcium sulphate has traditionally been used in Sherry [7-10] and Port winemaking [11]. More recently, Gómez et al. [12] recommended a combined acidification

\footnotetext{
a e-mail: juangomez.benitez@uca.es
}

with $2 \mathrm{~g} / \mathrm{L}$ of calcium sulphate and sufficient tartaric acid to achieve a $\mathrm{pH}$ of 3.25 . In this way, the necessary dose of tartaric acid does not exceed $1.5 \mathrm{~g} / \mathrm{L}$, the maximum authorized level in UE, and the final concentration of sulphates is lower than $2.5 \mathrm{~g} / \mathrm{L}$. Several chemical modeling approaches have been described with the aim of predicting the effect of acidification on $\mathrm{pH}$ and the general acidbase properties and ionic strength in white and red wines. Boulton [13] proposed a simple model in which the $\mathrm{pH}$ is expressed as a function of the titratable acidity, the potassium and sodium contents and the tartrate to malate ratio. Moreno and Peinado [14] updated and improved the model proposed by Usseglio-Tomasset [15] and developed a simple and easy to apply model. In this model the acidity of wine is considered to be due to a monoprotic acid and has been previously developed in $[16,17]$. In this model the effect on $\mathrm{pH}$ of adding $\mathrm{X}$ meq/L of tartaric acid can be predicted with the following equation

$$
p H=p K_{v}+\log \frac{A A_{f}}{T A_{f}}=p K_{v}+\log \frac{A A_{i}-X}{T A_{i}+X}
$$

where $K v$ is the acidity constant, $A A$ is the ash alkalinity that can be calculated through the buffering power and TA is the total acidity. The subscripts " $i$ " and " $\mathrm{f}$ " denote initial and final states respectively. In this model it is considered that the medium is saturated in tartrate and, as a consequence, the addition of tartaric acid as an acidifying agent will introduce the common ion $\mathrm{HT}^{-}$(bitartrate) and this will precipitate naturally or during cold stabilization as 
potassium bitartrate. In this way, one can consider that all of the $\mathrm{HT}^{-}$added will precipitate as potassium bitartrate and this does not contribute to the titratable acidity [14].

The effect of $\mathrm{CaSO}_{4}$ in grape must is based on the displacement of the ionic equilibrium produced by the $\mathrm{Ca}^{2+}$ ion. The different ionic reactions considered give rise to the following global reaction:

$$
\mathrm{Ca}^{2+}+\mathrm{H}_{2} \mathrm{~T} \rightarrow \mathrm{CaT} \downarrow+2 \mathrm{H}^{+} .
$$

The release of these two protons leads to a decrease in the $\mathrm{pH}$ of the must.

The addition of $\mathrm{Y}$ meq/L of $\mathrm{CaSO}_{4}$ removes $\mathrm{Y}$ meq/L of tartrate and AA and TA will also decrease to the same extent. Therefore:

$$
\begin{aligned}
& A A_{f}=A A_{i}-Y \\
& T A_{f}=T A_{i}-Y
\end{aligned}
$$

and the final $\mathrm{pH}$ will be calculate with the following equation:

$$
p H=p K_{V}+\log \frac{A A_{f}}{T A_{f}}=p K_{v}+\log \frac{A A_{i}-Y}{T A_{i}-Y} .
$$

In the combined acidification with $\mathrm{X}$ meq/L of tartaric acid and $\mathrm{Y}$ meq/L of calcium sulphate the final $\mathrm{pH}$ will be calculated with the equation:

$$
p H=p K_{V}+\log \frac{A A_{f}}{T A_{f}}=p K_{v}+\log \frac{A A_{i}+Y-X}{T A_{i}+X} .
$$

The aim of the work described here was to confirm at industrial scale the results previously obtained at pilot scale and facilitate its application at industrial scale by linear regression lines obtained with pilot scale date. At the same time, a deep analysis of the sensory effects of the different acidifiers will be made.

\section{Materials and methods}

\subsection{Description of the winemaking process}

The must for pilot scale tests was obtained in a previous harvest in a winery in the Jerez area from Palomino Fino variety grapes pressed at less than 1.0 bar. Tests were carried out in $25 \mathrm{~L}$ stainless steel tanks, where the must was acidified with calcium sulphate and/or tartaric acid and mixed with a paddle stirrer for $5 \mathrm{~min}$. After a settling period of $12 \mathrm{~h}$ musts were clear decanted to glass bottles of $16 \mathrm{~L}$ and inoculated with active dry yeast of $S$. cerevisiae, previously rehydrated. Musts were fermented in a thermostatic chamber at $25^{\circ} \mathrm{C}$.

Industrial scale tests were conducted in three different wineries during the harvest of 2014 and 2015. These musts were stored in stainless steel tanks of $22.000 \mathrm{~L}$, and acidified after filling the tanks. Acidified musts were stirred with mechanical systems to ensure a good mix of acidifying and settled for at least $18 \mathrm{~h}$ at a controlled temperature, then fermenting in stainless steel tanks at $20^{\circ} \mathrm{C}$ with selected dry yeast of $S$. cerevisiae inoculum. It must be emphasized that the harvest of 2014 was unusual because of the mild summer, which produced musts with low $\mathrm{pH}$ that needed dose of acidifier lower than usual, while 2015 was a normal harvest, from this point of view.

\subsection{Sample preparation}

Samples before fermentation were taken of settled clear musts. Samples after fermentation were taken fifteen days after the end of alcoholic fermentation. An additional sampling was carried out 2 months after the end of fermentation. All samples were centrifuged and filtered through $8 \mu \mathrm{m}$ membrane before analysis and the fermented ones were also ultrasound degassed to remove $\mathrm{CO}_{2}$. All tests and analysis were performed in duplicate and average values are given in the tables.

\subsection{Analytical methods}

The $\mathrm{pH}$, total acidity, potassium, calcium and sulphates were analysed by the official European Union analysis methods [18]. Buffering power was determined by titration until $\mathrm{pH}=3.0$ with $\mathrm{HCl} 0.1 \mathrm{~N}$. The results are expressed in meq/L $\mathrm{pH}$ unit. Tartaric acid was determined by colorimetric method [19].

\subsection{Equipment}

pH-meter: Metrohm $780 \mathrm{pH}$ Meter. Atomic absorption spectrophotometer: Perkin-Elmer Model Analyst 100. Multiparametric: I. S. E. Group Miura One 15.

\subsection{Reagents}

All laboratory reagents were of analytical grade. The water for the preparation of solutions and controls was Milli$\mathrm{Q}^{\circledR}$ (Type I). Calcium sulphate and tartaric acid were food quality and were added directly to the must and stirred until they were dissolved.

\subsection{Sensory analysis}

Sensory analysis of samples was made two months after fermentations and carried out by the tasters panel of Jerez-Xérèz-Sherry Regulator Council, composed by 21 tasters and trained with ISO 8586:2012 criteria [20]. Two different sensory tests were made, a triangle test to find differences among acidifiers and a preference test to determine which acidifier was preferred. The triangle test was made according [21] and in the preference test tasters had to range the samples according their preference from 1 (the best) to 3 (the worst).

\subsection{Statistical treatment of data and modelling}

The initial processing of data, as well as the modelling were performed using Microsoft Excel 2013 ${ }^{\circledR}$ (for further details, see reference [19]). Statistical analyses and linear regression lines were performed using Statgraphics Centurion version 2.16.04 (StatPoint Technologies, USA).

\section{Results and discussion}

\subsection{Acidifier behaviors at pilot scale}

Considering the good $\mathrm{pH}$ predictions at pilot scale tests $[16,17]$, linear regression lines were calculated for every acidifier. For acidification with calcium sulphate the regression line equation is:

$$
\text { Predicted } \mathrm{pH}=0.0753+1.0258 \times \text { Real } \mathrm{pH} \text {. }
$$




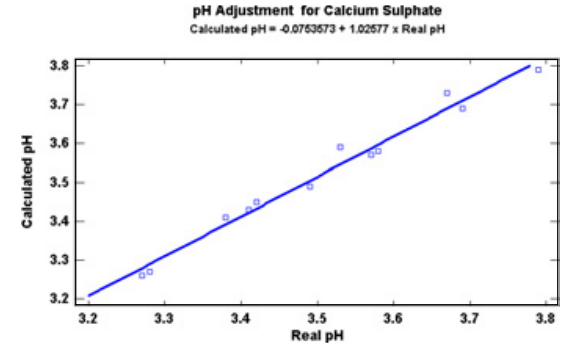

Figure 1. Real and calculated $\mathrm{pH}$ for acidification with calcium sulphate.

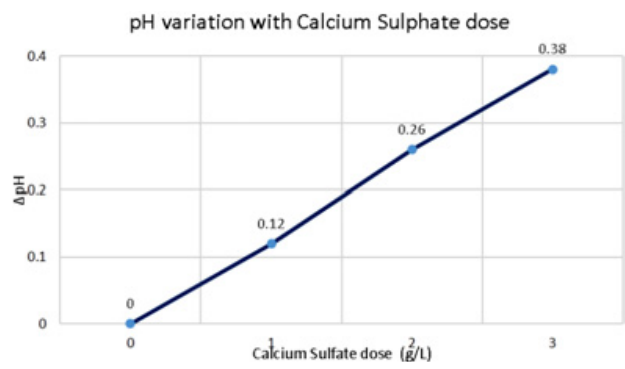

Figure 2. Acidifying effect of calcium sulphate.

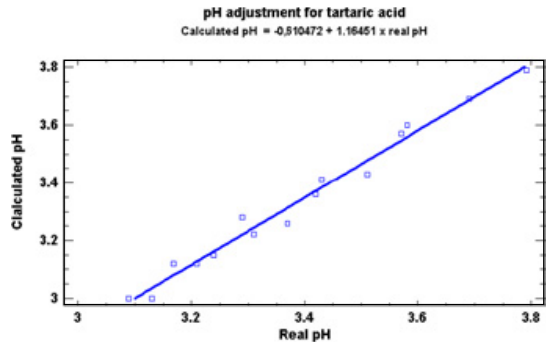

Figure 3. Real and calculated $\mathrm{pH}$ for acidification with tartaric acid.

Figure 1 shows real and predicted $\mathrm{pH}$ for calcium sulphate acidification. As can be seen, this model provides a good prediction of the experimental values of $\mathrm{pH}$ during all stages of winemaking. The agreement between actual and predicted values is very good and mistakes are lower than $0.1 \mathrm{pH}$ units.

The acidifying effect of different doses of calcium sulphate is shown in Fig. 2. This effect and can be estimated at 0.13 units/g calcium sulfate/L and remains constant with increasing dose.

The adjustment of $\mathrm{pH}$ for acidification with tartaric acid is shown in Fig. 3 where it is again observed good agreement between experimental values and calculated $\mathrm{pH}$. In general, errors are very low, less than $0.15 \mathrm{pH}$ units, what can be considered a very good result. The linear regression line equation is:

$$
\text { Predicted } \mathrm{pH}=-0.6105+1.1645 \times \text { real } \mathrm{pH} .
$$

Furthermore, as shown in Fig. 4, the effect of tartaric acid on the $\mathrm{pH}$ of the must can be estimated as an average of $0.17 \mathrm{~g} / \mathrm{L}$ and it seems to decrease as the dose increases.

In the combined acidification with calcium sulphate and tartaric acid different doses were added to provide a decrease in the $\mathrm{pH}$ to about 3.25 and shown in Fig. 5. In this case, the linear regression line equation is:

$$
\text { Predicted } \mathrm{pH}=-0.4034+1.1143 \times \text { real } \mathrm{pH} .
$$

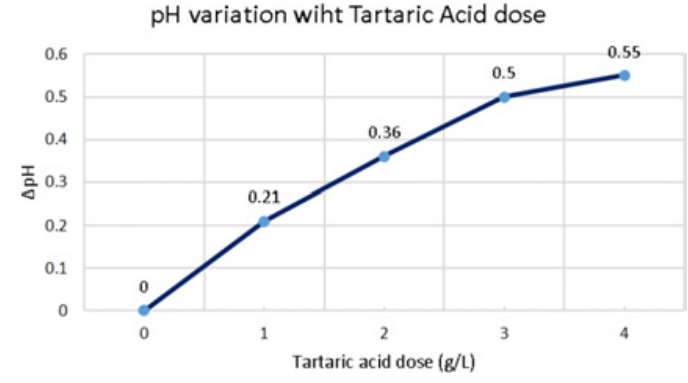

Figure 4. Acidifying effect of tartaric acid.

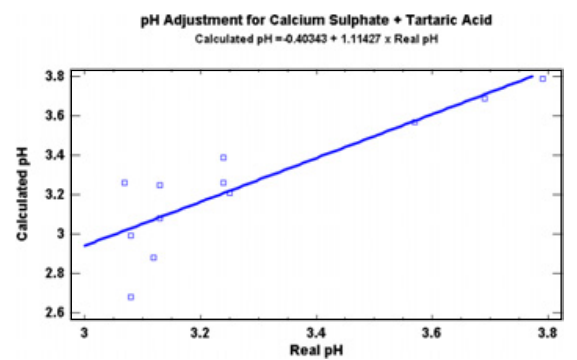

Figure 5. Real and calculated $\mathrm{pH}$ for acidification with calcium sulphate and tartaric acid.

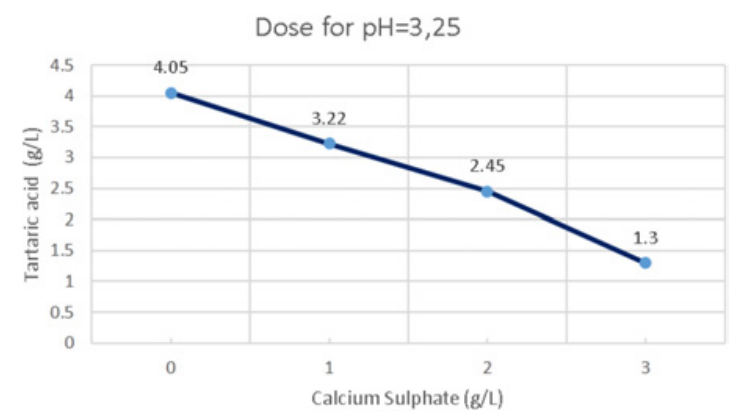

Figure 6. Necessary doses of calcium sulphate and tartaric acid to reach $\mathrm{pH}=3.25$.

As it can be seen the results for the $\mathrm{pH}$ prediction are not as good as in the cases of single acidification, the errors being less than $0.2 \mathrm{pH}$ units with only two main exceptions for higher doses of tartaric acid. This fact may be justified because the $\mathrm{pH}$ values are very close to the $\mathrm{pK}_{\mathrm{a} 1}$ (3.03), which could be considered as a critical point in the balance of acid dissociation. But errors occur after fermentation and not before fermentation, when they are really necessary to acidify from a practical point of view.

Figure 6 shows graphically the dose of calcium sulphate and tartaric acid needed to reach a $\mathrm{pH}$ of 3.25.

\subsection{Acidifier behavior of calcium sulphate and tartaric acid at industrial scale}

The study at industrial scale was carried out in two different wineries in the harvests of 2014 and 2015. The doses of acidifiers and the real and calculated $\mathrm{pH}$ values are shown in Tables 1 and 2 . As it can be seen from the results shown in both tables, average errors in $\mathrm{pH}$ predictions were 0.07 units before fermentation, 0.10 units after fermentation and 0.21 units two months after fermentation, what implies an excellent behavior, especially before fermentation, despite the difficulties of applying the methodology described at industrial scale. 
Table 1. Acidification with calcium sulphate and tartaric acid at industrial scale. Harvest 2014.

\begin{tabular}{|c|c|c|c|c|c|c|}
\hline \multirow[b]{2}{*}{ STAGE } & \multirow[b]{2}{*}{ Cellar } & \multicolumn{2}{|c|}{ Dose } & \multirow[b]{2}{*}{ Real pH } & \multirow[b]{2}{*}{ Calculated pH } & \multirow[b]{2}{*}{ Absolute Error } \\
\hline & & $\mathrm{CaSO}_{4}(\mathrm{~g} / \mathrm{L})$ & $\mathbf{H}_{\mathbf{2}} \mathbf{T}(\mathrm{g} / \mathrm{L})$ & & & \\
\hline \multirow{4}{*}{ BEFORE AF ${ }^{1}$} & 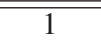 & 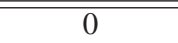 & 0.4 & 3.22 & 3.18 & 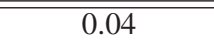 \\
\hline & 1 & 1.0 & 0.4 & 3.12 & 3.12 & 0.00 \\
\hline & 2 & 1.0 & 1.17 & 3.37 & 3.32 & 0.05 \\
\hline & \multicolumn{3}{|c|}{ AVERAGE } & 3.25 & 3.21 & 0.04 \\
\hline \multirow{4}{*}{ AFTER AF ${ }^{1}$} & 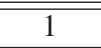 & 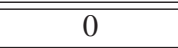 & 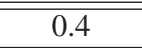 & 3.14 & 3.08 & 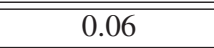 \\
\hline & 1 & 1.0 & 0.4 & 3.13 & 3.22 & 0.09 \\
\hline & 2 & 1.0 & 1.17 & 3.17 & 3.12 & 0.05 \\
\hline & \multicolumn{3}{|c|}{ AVERAGE } & 3.16 & 3.15 & 0.07 \\
\hline \multirow{4}{*}{$\begin{array}{l}2 \text { MONTS } \\
\text { LATER AF }\end{array}$} & 1 & 0 & 0.2 & 3.29 & 3.24 & 0.05 \\
\hline & 1 & 1.0 & 0.4 & 3.21 & 3.31 & 0.10 \\
\hline & 2 & 1.0 & 1.17 & 3.25 & 3.21 & 0.04 \\
\hline & \multicolumn{3}{|c|}{ AVERAGE } & 3.22 & 3.25 & 0.06 \\
\hline
\end{tabular}

${ }^{1} \mathrm{AF}$ : Alcoholic fermentation.

Table 2. Acidification with calcium sulphate and tartaric acid at industrial scale. Harvest 2015.

\begin{tabular}{|c|c|c|c|c|c|c|}
\hline \multirow[b]{2}{*}{ STAGE } & \multirow[b]{2}{*}{ Cellar } & \multicolumn{2}{|c|}{ Dose } & \multirow[b]{2}{*}{ Real pH } & \multirow[b]{2}{*}{ Calculated pH } & \multirow[b]{2}{*}{ Absolute Error } \\
\hline & & $\mathrm{CaSO}_{4}(\mathrm{~g} / \mathrm{L})$ & $\mathbf{H}_{2} \mathbf{T}(\mathrm{g} / \mathrm{L})$ & & & \\
\hline \multirow{7}{*}{ BEFORE AF ${ }^{1}$} & 1 & 2.0 & - & 3.61 & 3.63 & 0.02 \\
\hline & 2 & 2.0 & - & 3.46 & 3.34 & 0.12 \\
\hline & 1 & - & 1.20 & 3.54 & 3.41 & 0.13 \\
\hline & 2 & -- & 1.50 & 3.36 & 3.10 & 0.26 \\
\hline & 1 & 1.0 & 1.35 & 3.54 & 3.45 & 0.08 \\
\hline & 2 & 2.0 & 1.50 & 3.22 & 3.22 & 0.00 \\
\hline & \multicolumn{3}{|c|}{ AVERAGE } & 3.45 & 3.36 & 0.10 \\
\hline \multirow{7}{*}{ AFTER AF ${ }^{1}$} & 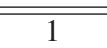 & 2.0 & - & 3.28 & 3.00 & 0.28 \\
\hline & 2 & 2.0 & - & 3.27 & 3.26 & 0.01 \\
\hline & 1 & - & 1.20 & 3.24 & 2.94 & 0.30 \\
\hline & 2 & - & 1.50 & 3.24 & 3.12 & 0.12 \\
\hline & 1 & 1.0 & 1.35 & 3.21 & 3.06 & 0.14 \\
\hline & 2 & 2.0 & 1.50 & 3.05 & 3.06 & 0.01 \\
\hline & \multicolumn{3}{|c|}{ AVERAGE } & 3.21 & 3.07 & 0.14 \\
\hline \multirow{7}{*}{2 MONTS LATER AF ${ }^{1}$} & 1 & 2.0 & - - & 3.42 & 3.00 & 0.42 \\
\hline & 2 & 2.0 & - & 3.28 & 2.43 & 0.85 \\
\hline & 1 & - & 1.20 & 3.36 & 3.09 & 0.27 \\
\hline & 2 & - & 1.50 & 3.27 & 2.70 & 0.57 \\
\hline & 1 & 1.0 & 1.35 & 3.28 & 3.15 & 0.13 \\
\hline & 2 & 2.0 & 1.50 & 3.01 & 3.01 & 0.00 \\
\hline & \multicolumn{3}{|c|}{ AVERAGE } & 3.27 & 2.90 & 0.37 \\
\hline
\end{tabular}

\footnotetext{
${ }^{1} \mathrm{AF}$ : Alcoholic fermentation.
}

Table 3. Sensory Analysis. Triangular test.

\begin{tabular}{|l|c|c|c|}
\hline \multicolumn{2}{|c|}{ Acidifiers } & Different & Probability \\
\hline $\mathbf{C a S O}_{\mathbf{4}}$ & $\mathbf{T H}_{\mathbf{2}}$ & Yes & $>99 \%$ \\
\hline $\mathbf{C a S O}_{4}$ & $\mathbf{C a S O}_{\mathbf{4}}+\mathbf{T H}_{\mathbf{2}}$ & Yes & $>99 \%$ \\
\hline $\mathbf{T H}_{\mathbf{2}}$ & $\mathbf{C a S O}_{\mathbf{4}}+\mathbf{T H}_{\mathbf{2}}$ & Yes & $>99 \%$ \\
\hline
\end{tabular}

Table 4. Preference test Preference levels $1>2>3$.

\begin{tabular}{|ll|c|c|}
\hline $\mathrm{CaSO}_{4}$ & $+\mathrm{TH}_{2}$ & $\mathrm{CaSO}_{4}$ & $\mathrm{TH}_{2}$ \\
\hline 1.29 & & 1.95 & 2.76 \\
\hline
\end{tabular}

\subsection{Sensory analysis}

The results of triangle test in Table 3 show that all acidifiers can be clearly differentiated by tasters.
The results of preference test in Table 4 show that the combined acidification with calcium sulphate and tartaric acid is the preferred option because gives softer acid taste meanwhile tartaric acid alone gives very acidic profile taste.

\section{Conclusions}

The prediction of $\mathrm{pH}$ of acidification at industrial scale can be made using the linear regression lines obtained with the results obtained at pilot scale with excellent results, especially before fermentation when acidification is normally made. It has also been verified that there are clear differences in sensory characteristic of wines acidified with different acidifiers and that tasters prefer the mixed acidification with calcium sulphate and tartaric acid. 
In consequence, it can be concluded that the use of calcium sulphate is still of great interest for must acidification in warm regions, and its use should be approved by the OIV.

\section{References}

[1] R.A. Plane, L.R. Mattick, L.D. Weirs, Am. J. Enol. Vitic. 31(3) 265-268 (1980)

[2] J.M Harris, P.E. Kriedermann, J.V. Possingham, Vitis 9 291-298 (1971)

[3] OIV. International Code of Oenological Practices. Issue (2016). Chemical acidification. Resolutions Oeno 3/99 and Oeno 13/01

[4] European Community. Council Regulation (EC) $\mathrm{N}^{\circ}$ 479/2008 Official Journal of the European Union L148 1-61 (2008)

[5] European Community. Commission Regulation (EC) $\mathrm{N}^{\circ} 606 / 2009$ Official Journal of the European Union L153 1-59 (2009)

[6] e-CFR.Electronic Code of Federal Regulations. (2010). Title 27: Alcohol, Tobacco and Firearms PART 24 WINE Subpart L Storage, Treatment and Finishing of Wine $\$ 24.246$ Materials authorized for the treatment of wine and juice. Available on line at http://www.ecfr.gov/cgi-bin/text-idx?SID= 5a39ba6737562446636a5b54a87b3961\&node= $27: 1.0 .1 .1 .19 .12$ \&rgn=div6\#27:1.0.1.1.19. 12.343.7, last accessed 5 September 2016

[7] Plinius Maior. (1st Century). Naturalis historiae, Book XIV, Chapter XIX

[8] G. Fernández de Bobadilla, J.M. Quirós, J.J. Serrano. Journal of the National Institute of Agronomic Research (INIA) 31 411-416 (1954)
[9] M.M. Gonzalez-Gordon. Sherry. The Noble Wine. (1972)

[10] J. Jeffs. Sherry ( $3^{\text {rd }}$ ed.). London (1982)

[11] M. A. S. Pato. De Vinea et vino Portugaliea Documenta, Serie II Enology,, Vol. 5( $\mathrm{N}^{\circ}$ 5) (1971)

[12] J. Gómez Benítez, M.M. Grandal Delgado, J. Díez Martín. Am. J. Enol. Vitic. 44(4) 400-404 (1993)

[13] R. Boulton Am. J. Enol. Vitic.31(2) 182-186 (1980)

[14] J. Moreno Vigara, R.A. Peinado Amores. Oenological Chemistry $\left(1^{\text {st }}\right.$ ed.). San Diego CA. (USA): Academic Press (2010)

[15] L. Usseglio-Tomasset, Chimica Enologica. Brescia. Italy: Ed. AEB(1995)

[16] J. Gómez, C. Lasanta, J.M. Palacios-Santander, L.M. Cubillana-Aguilera, Food Chem. 168 218-224 (2015)

[17] J. Gómez, C. Lasanta, L.M. Cubillana-Aguilera, J.M. Palacios Santander, R. Arnedo, J.A. Casas, L. Arroyo. 38 World Congress of Vine and Wine. BIO Web of Conferences 5, 02007 (2015). DOI: 10.1051/bioconf/20150502007

[18] European Community. Council Regulation (EEC) $\mathrm{N}^{\circ}$ 2676/90 Official Journal of the European Community L272 1-192 (1990)

[19] J. Trossais, C. Asselin, Vigne Vin $19 \mathbf{N}^{\circ} 4$ 249-259 (1965)

[20] ISO 8586:2012. Sensory analysis. General guidelines for the selection, training and monitoring of selected assessors and expert sensory assessors

[21] ISO 4120:2004 Sensory analysis. Methodology. Triangle test 